\title{
Garlic extract in bladder cancer prevention: Evidence from T24 bladder cancer cell xenograft model, tissue microarray, and gene network analysis
}

\author{
WON TAE KIM ${ }^{1,2}$, SUNG-PIL SEO ${ }^{2}$, YOUNG JOON BYUN ${ }^{1}$, HO-WON KANG ${ }^{1}$, YONG-JUNE KIM ${ }^{1,2}$, \\ SANG-CHEOL LEE ${ }^{1,2}$, PILDU JEONG ${ }^{1}$, YOONHEE SEO ${ }^{3}$, SOO YOUNG CHOE ${ }^{3,4}$, DONG-JOON KIM ${ }^{5}$, \\ SEON-KYU KIM ${ }^{6}$, SUNG-KWON MOON ${ }^{7}$, YUNG-HYUN CHOI ${ }^{8}$, GEUN TAEK LEE ${ }^{9}$, \\ ISAAC YI KIM ${ }^{9}$, SEOK JOONG YUN ${ }^{1,2}$ and WUN-JAE KIM ${ }^{1,2}$
}

\author{
${ }^{1}$ Department of Urology, Chungbuk National University College of Medicine; ${ }^{2}$ Department of Urology, \\ Chungbuk National University Hospital, Cheongju, Chungbuk 28644; ${ }^{3}$ EBO Co. Ltd., Cheongju, Chungbuk 28116; \\ ${ }^{4}$ Departmenrt of Biology, School of Life Sciences, Chungbuk National University, Cheongju, Chungbuk 28644; \\ ${ }^{5}$ TNT Research Co. Ltd., Anyang, Gyeonggi 14059; ${ }^{6}$ Medical Genomics Research Center, Korean Bioinformation Center, \\ Korea Research Institute of Bioscience and Biotechnology, Department of Functional Genomics, University of Science and \\ Technology, Daejeon 34113; ${ }^{7}$ School of Food Science and Technology, Chung-Ang University, Anseong, Gyeonggi 17546; \\ ${ }^{8}$ Department of Biochemistry, Dongeui University College of Oriental Medicine, Busan, South Gyeongsang 47340, \\ Republic of Korea; ${ }^{9}$ Section of Urological Oncology, The Cancer Institute of New Jersey, \\ Robert Wood Johnson Medical School, New Brunswick, NJ 08903, USA
}

Received January 27, 2017; Accepted March 7, 2017

DOI: 10.3892/ijo.2017.3993

\begin{abstract}
There is a growing interest in the use of naturally occurring agents in cancer prevention. This study investigated the garlic extract affects in bladder cancer (BC) prevention. The effect of garlic extract in cancer prevention was evaluated using the T24 BC BALB/C-nude mouse xenograft model. Microarray analysis of tissues was performed to identify differences in gene expression between garlic extract intake and control diet, and gene network analysis was performed to assess candidate mechanisms of action. Furthermore, we investigated the expression value of selected genes in the data of $165 \mathrm{BC}$ patients. Compared to the control group, significant differences in tumor volume and tumor weight were observed in the groups fed $20 \mathrm{mg} / \mathrm{kg}$ ( $\mathrm{p}<0.05), 200 \mathrm{mg} / \mathrm{kg}$, and $1000 \mathrm{mg} / \mathrm{kg}$ of garlic extract $(\mathrm{p}<0.01)$. Genes $(645)$ were identified as cancer prevention-related genes (fold change $>2$ and $\mathrm{p}<0.05)$ by tissue microarray analysis. A gene network analysis of 279 of these genes $(\mathrm{p}<0.01)$ was performed using
\end{abstract}

Correspondence to: Prof. Wun-Jae Kim or Prof. Seok Joong Yun, Department of Urology, College of Medicine, Chungbuk National University, 62 Kaeshin-dong, Heungduk-ku, Cheongju, Chungbuk 361-711, Republic of Korea

E-mail:wjkim@chungbuk.ac.kr

E-mail: sjyun@chungbuk.ac.kr

Key words: garlic, urinary bladder neoplasms, microarray analysis, gene regulatory networks, primary prevention
Cytoscape/ClueGo software: 36 genes and 37 gene ontologies were mapped to gene networks. Protein kinase A (PKA) signaling pathway including AKAP12, RDX, and RAB13 genes were identified as potential mechanisms for the activity of garlic extract in cancer prevention. In BC patients, AKAP12 and RDX were decreased but, RAB13 was increased. Oral garlic extract has strong cancer prevention activity in vivo and an acceptable safety profile. PKA signaling process, especially increasing AKAP12 and RDX and decreasing RAB13, are candidate pathways that may mediate this prevention effect.

\section{Introduction}

Bladder cancer $(\mathrm{BC})$ is the 7 th most common cancer in men and 17 th most common cancer in women worldwide. Smoking is the most common risk factor. Exposure to aromatic amines and polycyclic aromatic hydrocarbons is also a risk factor. Diet and environmental pollution are not clear risk factors in $\mathrm{BC}(1)$.

In recent years, there has been a growing interest in the use of naturally occurring agents for cancer prevention. Several meta-analyses showed that allium vegetable intake is associated with a reduced risk of several cancers (2,3). Garlic (Allium sativum L.), one of the most ancient medicinal plants, was first used to treat tumors in 1958 (4) and has been extensively studied in cancer ever since.

In garlic, the major anticancer organosulfur compounds are diallyl sulfide (DAS), diallyl disulfide (DADS), and diallyl trisulfide (DATS). These compounds can induce cell cycle arrest and apoptosis in cancer, especially BC, and, among 
them, DATS has the most potent anticancer activity $(5,6)$. The association between cancer prevention and garlic is generally under-studied and has not been studied at all in BC (5-8).

Cancer xenograft models are a useful source of tissue for array analysis when the availability of human clinical specimens is limited. The stromal component in mouse-derived, primary xenograft models have been successfully used for next-generation sequencing analysis in cancer (9).

Tissue microarray technology makes it possible to gain comprehensive insight into molecular mechanisms and can survey the RNA expression levels of more than 10,000 genes simultaneously (10). ClueGo and Cytoscape can provide a comprehensive view of a pathway or process among candidate genes in tissue microarray analysis $(11,12)$.

This study investigated whether garlic extract had activity in bladder cancer prevention in the T24 BC cell xenograft model and mechanisms were assessed by tissue microarray and gene network analysis. Furthermore, we investigated the expression value of selected genes in the data of $165 \mathrm{BC}$ patients.

\section{Materials and methods}

\section{Bladder tumor xenograft model}

Drugs. Garlic extract, a white powder of high purity (> Alliin $10 \mathrm{mg} / \mathrm{g}$ ), was obtained from Namhaegun Blackgarlic Co., Ltd. (Gyeongsangnam-do, Korea).

Cell line and cell culture. The T24 cell line was grown in Dulbecco's modified Eagle's medium (DMEM, Gibco BRL, Grand Island, NY, USA) supplemented with $10 \%$ fetal bovine serum (FBS) (Gibco BRL) and antibiotic-antimycotic (x100) (Gibco BRL). As recommended by the supplier, American Type Culture Collection (ATCC, Manassas, VA, USA), cultures were incubated in a humidified atmosphere of $5 \%$ $\mathrm{CO}_{2}$ at $37^{\circ} \mathrm{C}$.

Animals. Male BALB/c-nude mice (5 weeks old, weighing 16-20 g) were used to establish the T24 xenograft tumor model and were purchased from Daehan Biolink Co., Ltd. (Eumsung, Chungbuk, Korea). The mice were housed in pathogen-free conditions with a constant temperature and humidity. All animal tests and experimental procedures were performed by EBO Co., Ltd. (Cheongju, Korea). All animal experiments were approved by the appropriate Institutional Review Boards of the EBO Co., Ltd. (EBOA-2015-4).

\section{Methods}

Tumor xenograft inoculation. Cells were grown in culture. After digestion with $0.25 \%$ trypsin at $37^{\circ} \mathrm{C}$, the cells were washed once in phosphate-buffered saline (PBS, Welgene Inc., Daegu, Korea) and the cell concentration was adjusted to $3.6 \times 10^{7} / \mathrm{ml}$ with PBS. The cell suspension was mixed (1:1) with Matrigel $^{\mathrm{TM}}$ (BD Biosciences, Franklin Lakes, NJ, USA; lot 4258010) and implanted into the scapular region of nude mice by subcutaneous (s.c.) injection $(0.2 \mathrm{ml})$. After 10 days of growth, tumor volume (TV) was assessed by measuring two perpendicular diameters ( $\mathrm{L}$, length; $\mathrm{W}$, width) every 3 days with an electronic caliper. TV was calculated according to the method developed by the American National Cancer Institute: $\mathrm{TV}=\left(\mathrm{L} \times \mathrm{W}^{2}\right) / 2$.
Diet. Mice were randomized into four groups $(n=6)$. After measuring body weight, the animals were administered garlic powder every day per os (po.) in $10 \mathrm{ml} / \mathrm{kg}$ : 1) distilled water $+0 \mathrm{mg} / \mathrm{kg}$ garlic powder (GP 0 group, negative control), 2) distilled water $+20 \mathrm{mg} / \mathrm{kg}$ garlic powder (GP 20 group), 3) distilled water $+200 \mathrm{mg} / \mathrm{kg}$ (GP 200 group), and 4) distilled water $+1000 \mathrm{mg} / \mathrm{kg}$ (GP 1000 group). After 21 days, T24 cells were implanted into each mouse. The mice were administered garlic powder for a total of 43 days.

Tumor growth evaluation. Relative TV was assessed by dividing the TV on different observation days by the starting TV. The mice were sacrificed on day 23 after inoculation. The tumor growth inhibition rate (IR) was also used as a reference test and calculated as follows: IR $(\%)=$ (tumor weight of control group - tumor weight of test group) / tumor weight of control group $\mathrm{x} 100 \%$.

Statistical analysis. Results were expressed as mean \pm SEM. Statistically significant differences were assessed by Mann-Whitney U test, a non-parametric test. The criterion for significance was $\mathrm{p}<0.05$.

Microarray and gene network analysis

RNA purification. RNA purity and integrity were evaluated using a ND-1000 Spectrophotometer (NanoDrop, Wilmington, DE, USA) and an Agilent 2100 Bioanalyzer (Agilent Technologies, Palo Alto, CA, USA).

Labeling and purification. Total RNA was amplified and purified using the TargetAmp-Nano labeling kit for the Illumina Expression BeadChip (Epicentre, Madison, WI, USA) to yield biotinylated cRNA according to the manufacturer's instructions. Briefly, $500 \mathrm{ng}$ of total RNA was reverse-transcribed to cDNA using a T7 oligo(dT) primer. Second-strand cDNA was synthesized, in vitro transcribed, and labeled with biotinNTP. After purification, the cRNA was quantified using the ND-1000 Spectrophotometer (NanoDrop).

Hybridization and data export. Labeled cRNA samples (750 ng) were hybridized to each Human HT-12 v4.0 Expression Beadchip for $17 \mathrm{~h}$ at $58^{\circ} \mathrm{C}$ according to the manufacturer's instructions (Illumina, Inc., San Diego, CA, USA). Detection of array signal was carried out using Amersham fluorolink streptavidin-Cy3 (GE Healthcare Bio-Sciences, Little Chalfont, UK) following the bead array manual. Arrays were scanned with an Illumina bead array reader confocal scanner according to the manufacturer's instructions.

Raw data preparation and microarray statistical analysis. The quality of hybridization and overall chip performance were monitored by visual inspection of both internal quality control checks and raw scanned data. Raw data were extracted using the software provided by the manufacturer [Illumina GenomeStudio v2011.1 (gene expression module v1.9.0)]. Array probes were transformed by logarithm and normalized by the quantile method. The statistical significance of the expression data was determined by independent t-test and fold change; the null hypothesis was an absence of difference between the groups. The false discovery rate was controlled by adjusting 

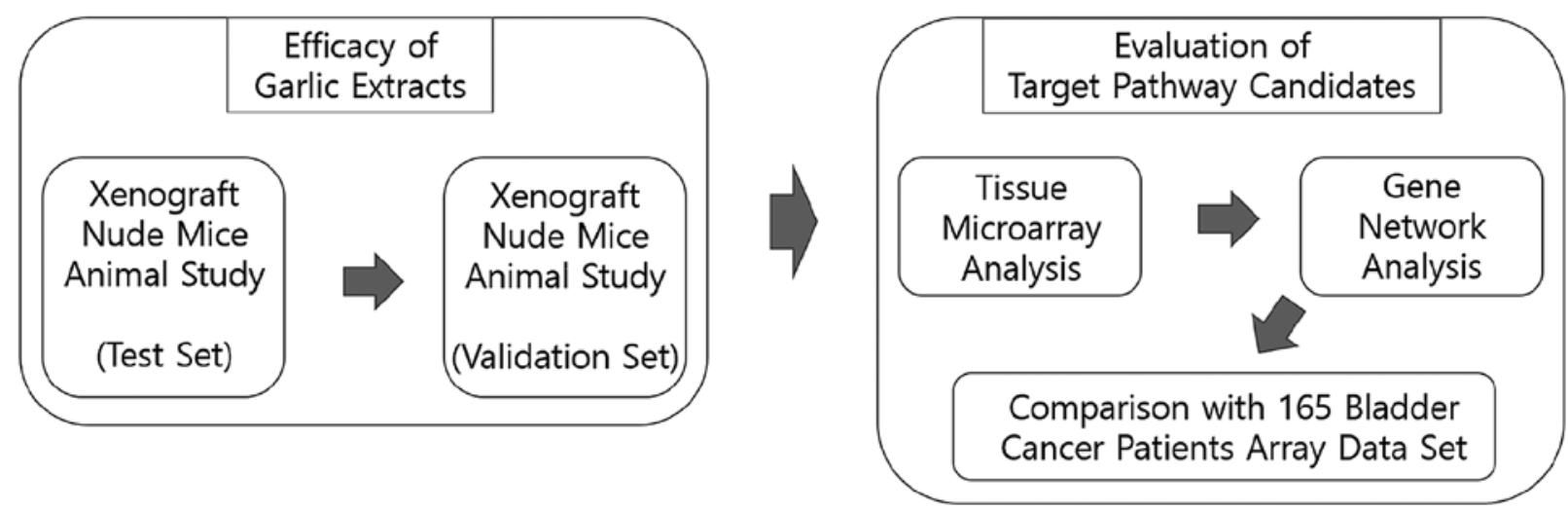

Figure 1. Schematic flow of the study design.
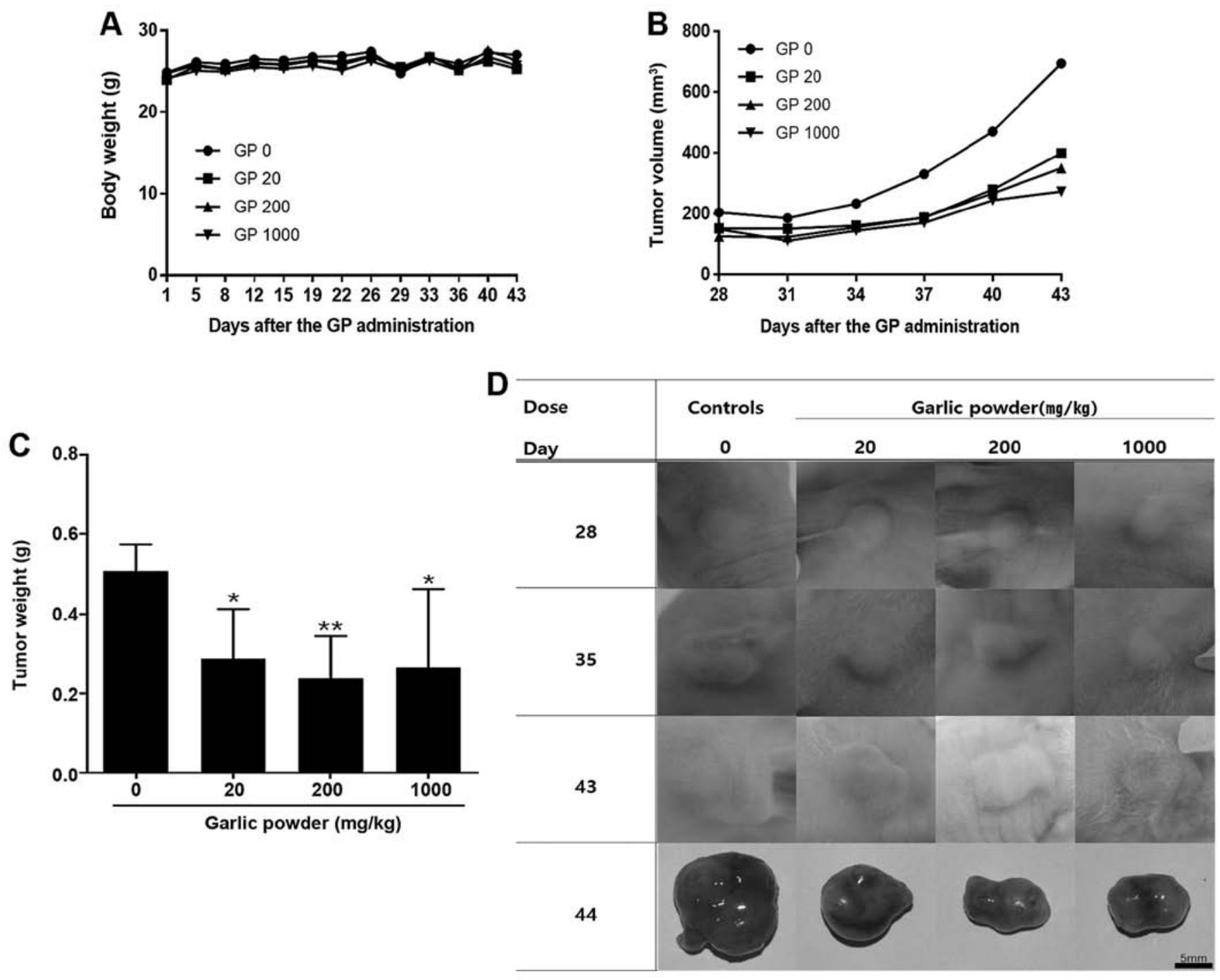

Figure 2. In vivo effect of garlic extract in the 1st T24 human bladder cancer xenograft study. (A) Body weight (g) of Balb/c-nude mice. (B) Tumor volume $\left(\mathrm{mm}^{3}\right)$ of Balb/c-nude mice. (C) Tumor weight (g) of Balb/c-nude mice. (D) Tumor shape after T24 cell implantation. GP 0, garlic powder 0 mg/kg, Control; GP 20, garlic powder $20 \mathrm{mg} / \mathrm{kg}$; GP 200, garlic powder $200 \mathrm{mg} / \mathrm{kg}$; GP 1000, garlic powder $1000 \mathrm{mg} / \mathrm{kg}$. ${ }^{*} \mathrm{P}<0.05 ;{ }^{* *} \mathrm{P}<0.01$.

the p-value using the Benjamini-Hochberg algorithm. For a DEG set, hierarchical cluster analysis was performed using complete linkage and Euclidean distance as a measure of similarity. Gene enrichment and functional annotation analysis was performed for significant probes using Gene Ontology (www.geneontology.org/). All data analysis and visualization of differentially expressed genes was conducted using R 3.1.2 (www.r-project.org). 

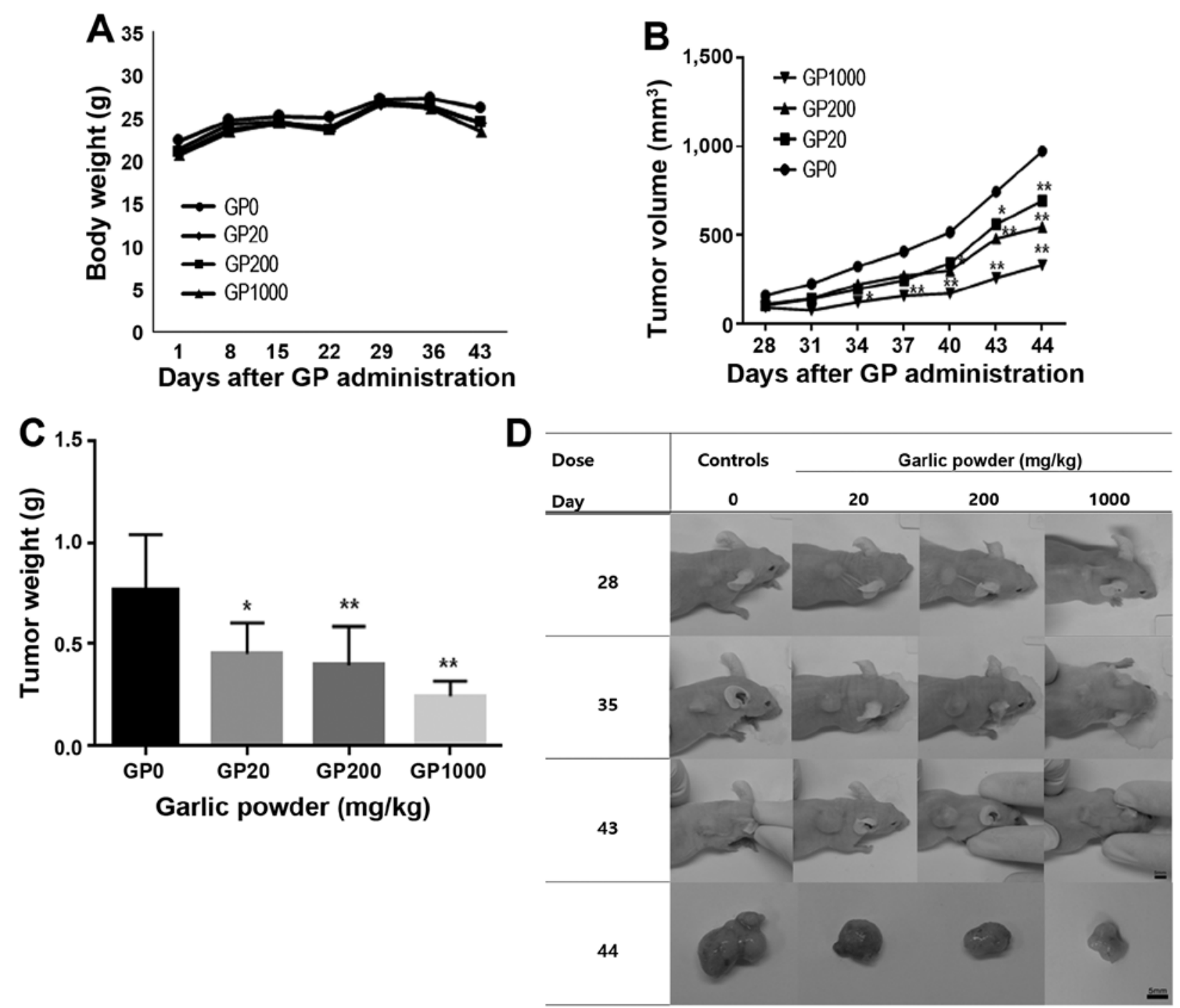

Figure 3. In vivo effect of garlic extract in the 2nd T24 human bladder cancer xenograft study. (A) Body weight (g) of Balb/c-nude mice. (B) Tumor volume $\left(\mathrm{mm}^{3}\right)$ of Balb/c-nude mice. (C) Tumor weight (g) of Balb/c-nude mice. (D) Tumor shape after T24 cell implantation. GP 0, garlic powder $0 \mathrm{mg} / \mathrm{kg}$, Control; GP 20, garlic powder $20 \mathrm{mg} / \mathrm{kg}$; GP 200, garlic powder $200 \mathrm{mg} / \mathrm{kg}$; GP 1000, garlic powder $1000 \mathrm{mg} / \mathrm{kg}$. ${ }^{*} \mathrm{P}<0.05$; ** $\mathrm{P}<0.01$.

Gene network analysis. Gene network analysis was performed using Cytoscape with ClueGo software.

Investigation of the expression of selected genes in 165 BC patient data. Independent $\mathrm{t}$-test was performed to identify the difference of gene expression between normal tissues vs. BC patient tissues. The BC patient data set is available in the NCBI Gene Expression Omnibus public database (microarray data, GSE13507) (13).

\section{Results}

Study overview. The workflow and overall study design are shown in Fig. 1.

Garlic extract inhibits the growth of xenograft tumors. There was no significant difference in body weight between the garlic extract groups $(20,200$, and $1000 \mathrm{mg} / \mathrm{kg}$ ) and control group (p $>0.05$, Fig. 2A). Compared to the control group, significant differences in TV and tumor weight were observed in the $20 \mathrm{mg} / \mathrm{kg}(\mathrm{p}<0.05), 200 \mathrm{mg} / \mathrm{kg}$ and $1000 \mathrm{mg} / \mathrm{kg}(\mathrm{p}<0.01)$ garlic extract groups (Fig. 2B and C). In addition, TV decreased in a garlic extract concentration-dependent manner (Fig. 2D).

Validation of xenograft animal study. To confirm the preventive effect of garlic extract, a second xenograft animal study was performed. In this validation study, a similar effect was observed (Fig. 3).

Gene expression signature associated with the effect of garlic extract. To select cancer prevention-related genes, 19,805 genes were selected by logarithm and normalization among 47,323 genes showing changes in expression levels in the $1000 \mathrm{mg} / \mathrm{kg}$ garlic extract group compared to control. Further, 645 genes were selected based on fold change and independent $\mathrm{t}$-test analysis (fold change $>2$ and $\mathrm{p}<0.05$ ). Cluster analysis was performed and a hierarchical clustering heatmap is shown in Fig. 4.

Interpretation of the garlic extract cancer prevention gene signature by gene network analysis. To identify predominant signaling networks in the cancer prevention effect of garlic 


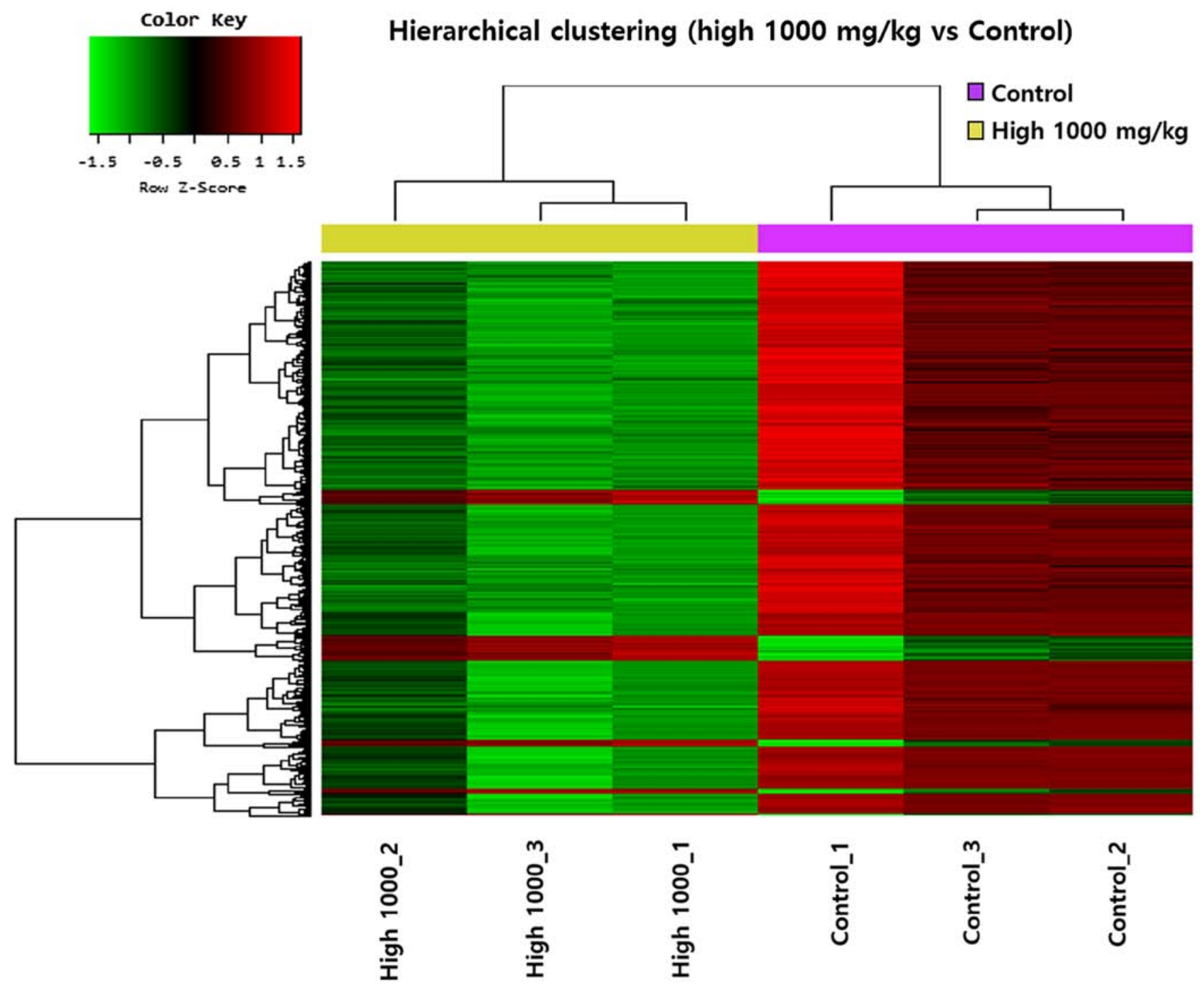

Figure 4. Hierarchical cluster analysis comparing garlic $1000 \mathrm{mg} / \mathrm{kg}$ groups to control. Genes with expression values that had a $\mathrm{p}<0.01$ and fold change $>2 \mathrm{were}$ selected (279 genes) for hierarchical analysis. The red and green reflect high and low expression levels, respectively.

extract, 279 genes were selected based on $p<0.01$. Gene network analysis of these 279 genes was carried out using Cytoscape with ClueGo software. Of the 279 genes, 36 genes and 37 gene ontologies were mapped to gene networks defined by this tool. The eight highest scoring networks are candidate mechanisms of action (Fig. 5 and Table I).

Expression value of the selected genes with 165 BC patient data sets. Of the selected 36 genes, 4 genes (AKAP12, IRS2, RDX, and UFM1) were significantly increased in garlic feeding groups, but decreased in BC patients (Table II). Ten genes (RAB13, PLA2G2D, OPA3, POLR1B, SSTR2, SPG7, RBM14, BMP8B, RAD51, and CDK10) were significantly decreased in garlic feeding groups, but increased in BC patients. AKAP12, RDX, and RAB13 are the associated genes with PKA signaling pathway.

\section{Discussion}

The present study identified bladder cancer (BC) preventive effects in garlic extract. This study is the first of its kind to investigate the cancer preventive effect of garlic extract using a $\mathrm{BC}$ xenograft model in BALB/c-nude mice. Tissue microarray analysis and gene network analysis were performed. Candidate mechanisms of action were identified, including protein kinase A (PKA) signaling process especially increasing AKAP12 and RDX, and decreasing RAB13.

In $\mathrm{BC}$, most of the cancer prevention studies testing garlic have been conducted in vitro using BC cells (5-7). Several cancer prevention studies tested garlic in ovarian, pancreatic, esophageal, and hepatocellular cancers (14-17). Until the present study, garlic in BC prevention has not been tested using xenograft models. The advantage of xenograft models is their use of human tumor cells featuring the complexity of the genetic and epigenetic abnormalities that exist in human tumors and their suitability to test individualized molecular therapeutic approaches (18).

The present in vivo study was performed with and without garlic extract, and tissue microarray analysis using tumor tissues was employed to identify candidate cancer preventive mechanisms. The advantage of tissue microarray analysis after giving garlic extract per os is the simultaneous 


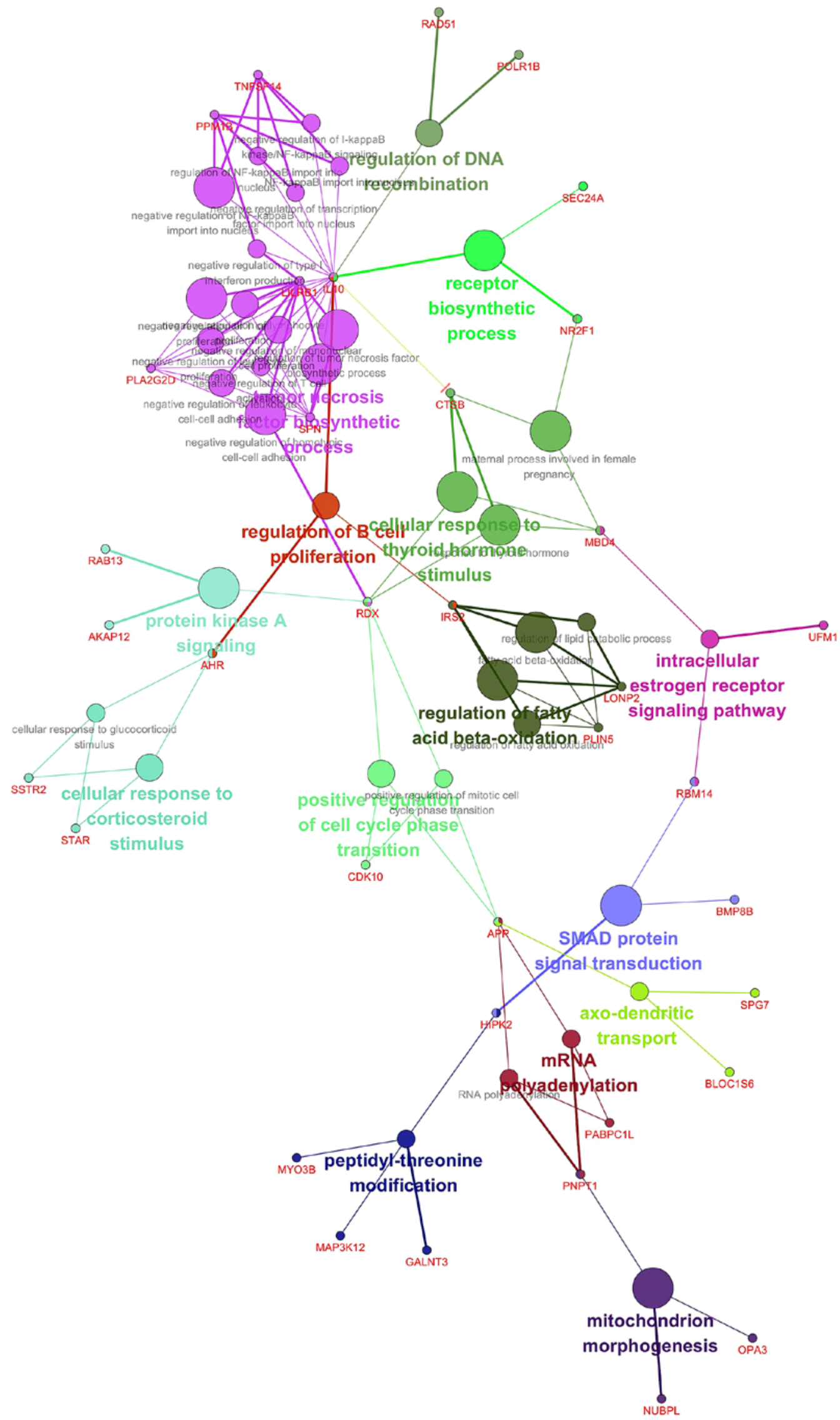

Figure 5. Gene network analysis of the candidate target pathways of garlic compounds. By gene network analysis, tumor necrosis factor biosynthetic process, regulation of B cell proliferation, regulation of DNA recombination, receptor biosynthetic process, cellular response to thyroid hormone stimulus, protein kinase A signaling, regulation of fatty acid $\beta$-oxidation, intracellular estrogen receptor signaling pathway, cellular response to corticosteroid stimulus, positive regulation of cell cycle phase transition, SMAD protein signal transduction, axo-dendritic transport, mRNA polyadenylation, peptidyl-threonine modification, and mitochondrion morphogenesis were possible candidate pathways. The networks were generated through the use of Cytoscape with ClueGo (www. cytoscape.org). 
Table I. Gene ontology and associated genes by gene network analysis using ClueGO.

\begin{tabular}{|c|c|c|c|}
\hline Gene ontology term & $\begin{array}{l}\text { No. } \\
\text { genes }\end{array}$ & $\begin{array}{c}\% \text { Associated } \\
\text { genes }\end{array}$ & Associated genes \\
\hline Tumor necrosis factor biosynthetic process & 3 & 13.636 & IL10, LILRB1, SPN \\
\hline Regulation of tumor necrosis factor biosynthetic process & 3 & 13.636 & IL10, LILRB1, SPN \\
\hline Negative regulation of leukocyte proliferation & 4 & 5.479 & IL10, LILRB1, PLA2G2D, SPN \\
\hline Negative regulation of type I interferon production & 3 & 6.383 & IL10, LILRB1, PPM1B \\
\hline Negative regulation of mononuclear cell proliferation & 4 & 5.797 & IL10, LILRB1, PLA2G2D, SPN \\
\hline Negative regulation of homotypic cell-cell adhesion & 5 & 4.808 & IL10, LILRB1, PLA2G2D, RDX, SPN \\
\hline Negative regulation of leukocyte cell-cell adhesion & 4 & 4.082 & IL10, LILRB1, PLA2G2D, SPN \\
\hline Negative regulation of $\mathrm{I}-\kappa \mathrm{B}$ kinase/NF- $\mathrm{KB}$ signaling & 3 & 5.172 & IL10, PPM1B, TNFSF14 \\
\hline Negative regulation of lymphocyte proliferation & 4 & 5.797 & IL10, LILRB1, PLA2G2D, SPN \\
\hline $\mathrm{NF}-\kappa \mathrm{B}$ import into nucleus & 3 & 6 & IL10, PPM1B, TNFSF14 \\
\hline Negative regulation of T-cell activation & 4 & 4.396 & IL10, LILRB1, PLA2G2D, SPN \\
\hline Regulation of NF- $\kappa \mathrm{B}$ import into nucleus & 3 & 6 & IL10, PPM1B, TNFSF14 \\
\hline Negative regulation of transcription factor import into nucleus & 3 & 6.122 & IL10, PPM1B, TNFSF14 \\
\hline Negative regulation of T-cell proliferation & 4 & 7.407 & IL10, LILRB1, PLA2G2D, SPN \\
\hline Negative regulation of $\mathrm{NF}-\kappa \mathrm{B}$ import into nucleus & 3 & 12 & IL10, PPM1B, TNFSF14 \\
\hline Regulation of B-cell proliferation & 3 & 4.762 & AHR, IL10, IRS2 \\
\hline Receptor biosynthetic process & 3 & 10.714 & IL10, NR2F1, SEC24A \\
\hline Regulation of DNA recombination & 3 & 4.68 & IL10, POLR1B, RAD51 \\
\hline Regulation of fatty acid $\beta$-oxidation & 3 & 16.667 & IRS2, LONP2, PLIN5 \\
\hline Regulation of fatty acid oxidation & 3 & 9.667 & IRS2, LONP2, PLIN5 \\
\hline Fatty acid beta-oxidation & 3 & 4 & IRS2, LONP2, PLIN5 \\
\hline Regulation of lipid catabolic process & 3 & 5.263 & IRS2, LONP2, PLIN5 \\
\hline Positive regulation of cell cycle phase transition & 3 & 4.762 & APP, CDK10, RDX \\
\hline Positive regulation of mitotic cell cycle phase transition & 3 & 5.172 & APP, CDK10, RDX \\
\hline mRNA polyadenylation & 3 & 7.143 & APP, PABPC1L, PNPT1 \\
\hline RNA polyadenylation & 3 & 6.977 & APP, PABPC1L, PNPT1 \\
\hline Cellular response to thyroid hormone stimulus & 3 & 21.429 & CTSB, MBD4, RDX \\
\hline Response to thyroid hormone & 3 & 13.043 & CTSB, MBD4, RDX \\
\hline Maternal process involved in female pregnancy & 3 & 4 & CTSB, MBD4, NR2F1 \\
\hline Cellular response to corticosteroid stimulus & 3 & 4.615 & AHR, SSTR2, STAR \\
\hline Cellular response to glucocorticoid stimulus & 3 & 4.839 & AHR, SSTR2, STAR \\
\hline Axo-dendritic transport & 3 & 6.818 & APP, BLOC1S6, SPG7 \\
\hline Mitochondrion morphogenesis & 3 & 14.286 & NUBPL, OPA3, PNPT1 \\
\hline Intracellular estrogen receptor signaling pathway & 3 & 5.882 & MBD4, RBM14, UFM1 \\
\hline SMAD protein signal transduction & 3 & 4.478 & BMP8B, HIPK2, RBM14 \\
\hline Peptidyl-threonine modification & 4 & 4.651 & GALNT3, HIPK2, MAP3K12, MYO3B \\
\hline Protein kinase A signaling & 3 & 10.345 & AKAP12, RAB13, RDX \\
\hline
\end{tabular}

In gene ontology term, bold text is representative pathways among several pathways by gene network analysis. In \% associated gene, bold text is highly associated genes among them.

evaluation of the expression of more than 10,000 genes (19). Since cancer is a very complicated disease with multiple heterogeneous genetic and epigenetic changes, it is very difficult to evaluate the efficacy of garlic extract. Using tissue 
Table II. Comparisons of gene expression values between garlic animal model and data of $165 \mathrm{BC}$ patients.

\begin{tabular}{|c|c|c|c|c|}
\hline \multirow[b]{2}{*}{ Gene } & \multicolumn{2}{|c|}{ Garlic animal model } & \multicolumn{2}{|c|}{$165 \mathrm{BC}$ patients } \\
\hline & $\begin{array}{l}\text { Garlic feeding/ } \\
\text { controls }\end{array}$ & $\mathrm{p}$-value & $\begin{array}{c}\text { BC patients/ } \\
\text { normal }\end{array}$ & p-value \\
\hline AKAP12 & Up & 0.003 & Down & $<0.001$ \\
\hline IRS2 & Up & 0.001 & Down & $<0.001$ \\
\hline RDX & Up & 0.004 & Down & $<0.001$ \\
\hline UFM1 & Up & 0.003 & Down & $<0.001$ \\
\hline RAB13 & Down & 0.007 & $\mathrm{Up}$ & 0.017 \\
\hline PLA2G2D & Down & 0.003 & Up & 0.01 \\
\hline OPA3 & Down & 0.007 & Up & $<0.001$ \\
\hline POLR1B & Down & 0.002 & Up & $<0.001$ \\
\hline SSTR2 & Down & 0.002 & Up & 0.004 \\
\hline SPG7 & Down & 0.006 & Up & 0.022 \\
\hline RBM14 & Down & 0.006 & Up & $<0.001$ \\
\hline BMP8B & Down & 0.006 & $\mathrm{Up}$ & 0.023 \\
\hline RAD51 & Down & 0.005 & Up & $<0.001$ \\
\hline CDK10 & Down & 0.008 & $\mathrm{Up}$ & $<0.001$ \\
\hline
\end{tabular}

microarray analysis, several important key mechanisms of garlic extract were identified. Future studies will focus on these candidate mechanisms.

Several reports suggest that garlic extract induces cell cycle arrest and apoptosis and has antimutagenic properties in numerous cancer cells $(20,21)$. Milner suggested that garlic could suppress carcinogen formation, carcinogen bioactivation, and tumor proliferation (20). Further, garlic extract induced a caspase-independent apoptotic pathway mediated by mitochondrial release of AIF and PKA in human epithelial carcinoma cells (22). PKA belongs to a family of cyclic AMP-dependent holoenzymes and is involved in cell proliferation (23). This study suggested that the major candidate mechanisms of garlic for cancer prevention were PKA signaling mechanisms. AKAP12, RDX, and RAB13 appear to be key genes mediating the cancer prevention effect of garlic extract. Especially upregulation of AKAP12 and downregulation of RAB13 are important pathways for cancer prevention by garlic extracts.

AKAP12 is a member of the A-kinase anchoring protein family and was first isolated from the serum of myasthenia gravis patients (24). In cancer, AKAP12 has been downregulated in cancer tissue by promoter hypermethylation and might be involved in the suppression of cancer (25). In our BC data, AKAP12 was also downregulated in BC. Yoon et al reported that AKAP12 induces cell cycle arrest and subsequent apoptosis in cancer cells and also suggested that AKAP12 could antagonize cancer progression effectively (26). Several studies strongly suggested that AKAP12 gene acts as a tumor suppressor $(25,26)$. In our study, upregulated AKAP12 was found in garlic feeding group. Accordingly, garlic extracts might restore the activity of tumor suppressor of AKAP12.
The members of the RAB (Ras-related in brain) family of proteins are known as master regulators of vesicle trafficking. RAB13 is now recognized as an important driver of cancer progression (27). Consistent with a role for RAB13 in cancer progression, RAB13 is upregulated in many cancers $(28,29)$. In our BC data, RAB13 was also upregulated in BC. Ioannou et al (30) reported that RAB13 knockdown reduces cancer cell migration, invasion, and spread in vitro and in vivo study and showed that RAB13 plays an important role in promoting tumorigenicity. In our study, downregulated RAB13 was found in garlic feeding group, garlic extracts might inhibit the activity of cancer progression of RAB13.

RDX and its roles in cancer remain unclear. However, RDX decreased in BC patients and increased in garlic feeding group. Probably, RDX has a tumor suppressive role like AKAP12 in cancer. PCR validation and in vitro functional validation of these data will be performed in future studies.

In conclusion, garlic extract intake has strong cancer prevention activity in vivo and a suitable safety profile. Using tissue microarray and gene network analysis, PKA signaling process, especially increasing AKAP12 and RDX and decreasing RAB13, appear as possible mechanisms underlying this cancer prevention effect. Further functional in vitro studies and large human clinical trials are necessary to validate this study.

\section{Acknowledgements}

This work was supported by a National Research Foundation of Korea (NRF) grant funded by the Korean government (MSP) (no. 2014R1A2A2A04007036) and by the Functional Districts of the Science Belt support program, Ministry of Science, ICT and Future Planning (2016K000297). We thank Bioedit services for assistance with language editing.

\section{References}

1. Burger M, Catto JW, Dalbagni G, Grossman HB, Herr H, Karakiewicz P, Kassouf W, Kiemeney LA, La Vecchia C, Shariat $\mathrm{S}$, et al: Epidemiology and risk factors of urothelial bladder cancer. Eur Urol 63: 234-241, 2013.

2. Kodali RT and Eslick GD: Meta-analysis: Does garlic intake reduce risk of gastric cancer? Nutr Cancer 67: 1-11, 2015.

3. Guercio V, Turati F, La Vecchia C, Galeone C and Tavani A: Allium vegetables and upper aerodigestive tract cancers: A meta-analysis of observational studies. Mol Nutr Food Res 60: 212-222, 2016.

4. Butt MS, Sultan MT, Butt MS and Iqbal J: Garlic: Nature's protection against physiological threats. Crit Rev Food Sci Nutr 49: 538-551, 2009.

5. Shin DY, Kim GY, Hwang HJ, Kim WJ and Choi YH: Diallyl trisulfide-induced apoptosis of bladder cancer cells is caspasedependent and regulated by PI3K/Akt and JNK pathways. Environ Toxicol Pharmacol 37: 74-83, 2014.

6. Wang YB, Qin J, Zheng XY, Bai Y, Yang K and Xie LP: Diallyl trisulfide induces Bcl-2 and caspase-3-dependent apoptosis via downregulation of Akt phosphorylation in human T24 bladder cancer cells. Phytomedicine 17: 363-368, 2010.

7. Shin DY, Cha HJ, Kim GY, Kim WJ and Choi YH: Inhibiting invasion into human bladder carcinoma 5637 cells with diallyl trisulfide by inhibiting matrix metalloproteinase activities and tightening tight junctions. Int J Mol Sci 14: 19911-19922, 2013.

8. Hu H, Zhang XP, Wang YL, Chua CW, Luk SU, Wong YC, Ling MT, Wang XF and Xu KX: Identification of a novel function of Id-1 in mediating the anticancer responses of SAMC, a watersoluble garlic derivative, in human bladder cancer cells. Mol Med Rep 4: 9-16, 2011. 
9. Rossello FJ, Tothill RW, Britt K, Marini KD, Falzon J, Thomas DM, Peacock CD, Marchionni L, Li J, Bennett S, et al: Next-generation sequence analysis of cancer xenograft models. PLoS One 8: e74432, 2013.

10. Quackenbush J: Microarray analysis and tumor classification. N Engl J Med 354: 2463-2472, 2006.

11. Bindea G, Mlecnik B, Hackl H, Charoentong P, Tosolini M, Kirilovsky A, Fridman WH, Pagès F, Trajanoski Z and Galon J: ClueGO: A Cytoscape plug-in to decipher functionally grouped gene ontology and pathway annotation networks. Bioinformatics 25: 1091-1093, 2009.

12. Bindea G, Galon J and Mlecnik B: CluePedia Cytoscape plugin: Pathway insights using integrated experimental and in silico data. Bioinformatics 29: 661-663, 2013.

13. Kim WJ, Kim EJ, Kim SK, Kim YJ, Ha YS, Jeong P, Kim MJ, Yun SJ, Lee KM, Moon SK, et al: Predictive value of progressionrelated gene classifier in primary non-muscle invasive bladder cancer. Mol Cancer 9: 3, 2010.

14. Wu J, Zhao S, Zhang J, Qu X, Jiang S, Zhong Z, Zhang F, Wong $\mathrm{Y}$ and Chen $\mathrm{H}$ : Over-expression of survivin is a factor responsible for differential responses of ovarian cancer cells to S-allylmercaptocysteine (SAMC). Exp Mol Pathol 100: 294-302, 2016.

15. Wang W, Cheng J and Zhu Y: The JNK signaling pathway is a novel molecular target for S-propargyl-L-cysteine, a naturallyoccurring garlic derivatives: link to its anticancer activity in pancreatic cancer in vitro and in vivo. Curr Cancer Drug Targets 15: 613-623, 2015.

16. Yin X, Zhang J, Li X, Liu D, Feng C, Liang R, Zhuang K, Cai C, Xue X, Jing F, et al: DADS suppresses human esophageal xenograft tumors through RAF/MEK/ERK and mitochondriadependent pathways. Int J Mol Sci 15: 12422-12441, 2014.

17. Ng KT, Guo DY, Cheng Q, Geng W, Ling CC, Li CX, Liu XB, Ma YY,Lo CM, Poon RT, et al: A garlic derivative, S-allylcysteine (SAC), suppresses proliferation and metastasis of hepatocellular carcinoma. PLoS One 7: e31655, 2012.

18. Richmond A and Su Y: Mouse xenograft models vs. GEM models for human cancer therapeutics. Dis Model Mech 1: 78-82, 2008.

19. Russo G, Zegar C and Giordano A: Advantages and limitations of microarray technology in human cancer. Oncogene 22 : 6497-6507, 2003.

20. Milner JA: A historical perspective on garlic and cancer. J Nutr 131: S1027-S1031, 2001
21. Tsai CW, Chen HW, Yang JJ, Sheen LY and Lii CK: Diallyl disulfide and diallyl trisulfide up-regulate the expression of the pi class of glutathione S-transferase via an AP-1-dependent pathway. J Agric Food Chem 55: 1019-1026, 2007.

22. Park SY, Cho SJ, Kwon HC, Lee KR, Rhee DK and Pyo S: Caspase-independent cell death by allicin in human epithelial carcinoma cells: Involvement of PKA. Cancer Lett 224: 123-132, 2005.

23. Cho-Chung YS: Role of cyclic AMP receptor proteins in growth, differentiation, and suppression of malignancy: New approaches to therapy. Cancer Res 50: 7093-7100, 1990.

24. Gordon T, Grove B, Loftus JC, O'Toole T, McMillan R, Lindstrom $\mathrm{J}$ and Ginsberg MH: Molecular cloning and preliminary characterization of a novel cytoplasmic antigen recognized by myasthenia gravis sera. J Clin Invest 90: 992-999, 1992.

25. Hayashi M, Nomoto S, Kanda M, Okamura Y, Nishikawa Y, Yamada S, Fujii T, Sugimoto H, Takeda S and Kodera Y: Identification of the A kinase anchor protein 12 (AKAP12) gene as a candidate tumor suppressor of hepatocellular carcinoma. J Surg Oncol 105: 381-386, 2012.

26. Yoon DK, Jeong CH, Jun HO, Chun KH, Cha JH, Seo JH, Lee HY, Choi YK, Ahn BJ, Lee SK, et al: AKAP12 induces apoptotic cell death in human fibrosarcoma cells by regulating CDKI-cyclin D1 and caspase-3 activity. Cancer Lett 254: 111-118, 2007.

27. Ioannou MS and McPherson PS: Regulation of cancer cell behavior by the small GTPase Rab13. J Biol Chem 291: 9929-9937, 2016.

28. Mahadevan D, Spier C, Della Croce K, Miller S, George B, Riley C, Warner S, Grogan TM and Miller TP: Transcript profiling in peripheral T-cell lymphoma, not otherwise specified, and diffuse large B-cell lymphoma identifies distinct tumor profile signatures. Mol Cancer Ther 4: 1867-1879, 2005.

29. Li W, Li K, Zhao L and Zou H: Bioinformatics analysis reveals disturbance mechanism of MAPK signaling pathway and cell cycle in glioblastoma multiforme. Gene 547: 346-350, 2014.

30. Ioannou MS, Bell ES, Girard M, Chaineau M, Hamlin JN, Daubaras M, Monast A, Park M, Hodgson L and McPherson PS: DENND2B activates Rab13 at the leading edge of migrating cells and promotes metastatic behavior. J Cell Biol 208: 629-648, 2015. 